\title{
PENGEMBANGAN MEDIA PEMBELAJARAN \\ PELUANG BERBASIS MULTIMEDIA INTERAKTIF \\ UNTUK MAHASISWA INSTITUT PESANTREN \\ KH.ABDUL CHALIM
}

\section{Dewi Nuur Rahmasari, M.Pd \\ E-mail Dewi.rahmasari22@gmail.co}

\begin{abstract}
Abstrak: This research aims at developing interactive multimedia-based mathematical learning and revealing how the students' respond toward the media are. The development steps of that interactive mathematical learning media using computer were carried out by development model of ADDIE (Analysis, Design, Development, Implementation, Evaluation). The instrument used to collect the data was media evaluation questionnaires. The data analysis technique was conducted both qualitatively and quantitatively. Based on the research findings that the interactive multimedia-based probability learning revealed no revision and wellreceived by the students. Although there is difficulty for the students at the initial use of it, due to abstract learning habit, but it can be overcome well.
\end{abstract}

Keywords: development; media; probability; interactive multimedia 


\section{A. PENDAHULUAN}

Dewasa ini kegiatan pembelajaran lebih diartikan sebagai upaya aktif dosen untuk membantu mahasiswa dalam membangun pengetahuannya dengan menggunakan pengalaman-pengalaman atau pengetahuan-pengetahuan yang telah dimiliki mahasiswa sebelumnya. Dosen lebih sebagai fasilitator yang memberikan kesempatan kepada mahasiswa untuk membangun pengetahuannya melalui aktivitas pembelajaran. Maka dengan menggunakan media pembelajaran diharapkan mahasiswa lebih mudah membangun pengetahuan matematika yang sudah ada pada dirinya sesuai dengan tema pembelajaran.

Computer merupakan salah satu alternatif media yang dapat membantu siswa untuk melakukan banyak eksplorasi dalam waktu yang terbatas. Maka dari itu peneliti pada kesempatan ini untuk membantu mengembngkan media pembelajarannya menggunakan media komputer. Dalam pembelajaran konsepkonsep yang menuntut ketelitian tinggi, konsep atau prinsip yang repetitif, penyelesaiaan grafik secara tepat, cepat dan akurat program komputer sangat ideal untuk dimanfaatkan. Media pembelajaran berbasis komputer yang mutakhir meliputi text, graphic, audio, dan video yang dibuat, dikemas, disajikan, dan dimanfaatkan secara interaktif melalui komputer. Media 
pembelajaran matematika yang demikian disebut media pembelajaran matematika berbasis multimedia interaktif.

Mengingat tidak semua materi matematika tepat disampaikan menggunakan media berbasis komputer (multimedia interaktif). Oleh karena itu peneliti memilih dua pokok bahasan yang tepat pada mata kuliah Teori Peluang, yaitu adalah materi Kombinatorika dan Peluang. Selain alasan ketepatan materi, berdasarkan hasil observasi di lapangan dan dari hasil wawancara siswa diperoleh informasi bahwa materi peluang merupakan materi yang sulit

\section{B. KAJIAN TEORI}

a. Media Pembelajaran Berbasis Komputer

Penggunaan aplikasi komputer dalam dunia pendidikan khususnya yang digunakan dalam media pembelajaran dikenal dengan CAI (Computer Assisted Instruction) atau pembelajaran dengan bantuan komputer. Adapun ciri-ciri media pembelajaran berbasis komputer dikemukakan oleh Azhar Arsyad (2002: 32) sebagai berikut:

1. Dapat digunakan secara acak, non-sekuensial, atau secara linier;

2. Dapat digunakan berdasarkan keinginan siswa atau berdasarkan keinginan perancang sebagaimana direncanakannya; 
3. Gagasan-gagasan disajikan dalam gaya abstrak dengan kata, simbol, dan grafik;

4. Pembelajaran dapat berorientasi siswa dan melibatkan interaktivitas siswa yang tinggi.

Sementara pertimbangan penggunaan komputer sebagai media pembelajaran dikemukakan oleh Lee (Ouda Teda Ena, 2005) yang meliputi pengalaman, motivasi, meningkatkan pembelajaran, materi yang otentik, interaksi yang lebih luas, lebih pribadi, tidak terpaku pada sumber tunggal, dan pemahaman global.

b. Multimedia Interaktif

Beeckman dan Quinn (2005: 251) mengemukakan bahwa multimedia adalah sebagai kombinasi dari teks, grafis, animasi, video, musik, suara/narasi, dan efek suara digunakan untuk menyampaikan pesan atau informasi. Menurut Purwanto (2004: 1), multimedia interaktif terdiri dari teks, grafis, audio, dan video yang dibuat, dikemas, disajikan, dan dimanfaatkan secara interaktif melalui komputer. Lebih lanjut menurut Purwanto (2004: 3), terdapat prinsisp-prinsip yang harus diperhatikan untuk mengembangkan multimedia interaktif, yaitu:

1) Isinya harus sesuai dengan tujuan instruksional, akurat mutakhir, komprehensif, dan harus menyikapi ras, agama, dan jenis kelamin. 
2) Penyajiannya harus menarik, sistematis, mengikuti teoriteori belajar, dan mempergunakan bahasa yang tepat.

3) Penyajiannya harus memperhatikan tingkat kematangan anak.

4) Harus dilengkapi petunjuk penggunaan.

5) Kualitas fisiknya harus baik.

c. Kriteria Media Pembelajaran

Ouda Teda Ena (2005) mengemukakan media pembelajaran harus meningkatkan motivasi pembelajar. Penggunaan media mempunyai tujuan memberikan motivasi kepada pembelajar. Selain itu media juga harus merangsang pembelajar mengingat apa yang sudah dipelajari selain memberikan rangsangan belajar baru. Media yang baik juga akan mengaktifkan pembelajar dalam memberikan tanggapan, umpan balik dan juga mendorong siswa untuk melakukan praktik-praktik dengan benar. Jadi agar media yang dibuat dapat efektif dalam mencapai tujuan pembelajaran yang diharapkan perlu diperhatikan kriteriakriteria dalam penyusunannya.

Walker \& Hess (Azhar Arsyad, 2002: 175-176), memberikan kriteria dalam mereviuw perangkat lunak media pembelajaran yang berdasarkan kualitas, yang meliputi (1) Kualitas Isi dan tujuan: ketepatan, kelengkapan, kepentingan, keseimbangan, perhatian, keadilan, kesesuaian dengan situasi siswa (2) Kualitas Instruksional: memberikan kesempatan 
belajar, memberikan bantuan belajar, kualitas memotivasi, fleksibilitas instruksionalnya, dan (3) Kualitas Teknis: keterbacaan, mudah digunakan, kualitas tampilan.

\title{
C. METODE PENELITIAN
}

Penelitian ini merupakan jenis penelitian pengembangan, yaitu suatu proses penelitian yang digunakan untuk mengembangkan suatu produk yang efektif digunakan di dunia pendidikan, dan bukan digunakan untuk menguji teori. Produk yang dihasilkan adalah media pembelajaran berbasis multimedia interaktif pada pokok bahasan Kombinatorika dan Peluang. Langkah-langkah pengembangan media pembelajaran mengikuti model pengembangan ADDIE (Analysis, Design, Development, Implementation, Evaluation).

Teknik analisis dilaksanakan secara kualitatif dan kuantitatif. Teknik kualitatif digunakan untuk mendeskripsikan berbagai kendala yang ditemukan dosen pengampu yang dihadapi mahasiswa selama pembelajaran berlangsung. Hal apa saja yang tidak mendukung proses pembelajaran. Sedangkan teknik kuantitatif digunakan untuk mendeskripsikan pendapat mahasiswa yang tertuang dalam angket evaluasi media.

\author{
D. HASIL DAN PEMBAHASAN \\ a. Deskripsi Media Pembelajaran
}


Berikut ini tahap-tahap pengembangan untuk menghasilkan media pembelajaran peluang berbasis multimedia interaktif adalah sebagai berikut:

1) Analisis (Analysis)

a) Kurikulum materi peluang

Dilakukan untuk menentukan pokok bahasan mana yang cocok yang akan disampaikan dengan menggunakan media pembelajaran peluang berbasis interaktif. Peneliti memutuskan untuk memilih pokok bahasan kombinatorika dan peluang. Peneliti memutuskan memilih materi ini karena peneliti menganalisis mahasiswa masih banyak kesulitan dalam memahami materi kombinatorika terutama bingung dalam membedakan kombinasi dan permutasi.

b) Analisis karakteristik siswa

Diketahui bahwa Mahasiswa Institut Pesantren Khabdul Chalim sudah terbiasa menggunakan komputer. Akan tetapi belum terbiasa menggunakan program matematika. Karena tidak semua mata kuliah aplikasinya menggunakan program. Mahasiswa baru mempaktekkan menggunakan SPSS.

c) Analisis setting

Berdasarkan pengamatan di Kampus, situasi dan kondisi Institut Pesantren KH.Abdul Chalim sangat kondusif 
untuk melakukan pembelajaran dengan menggunakan komputer. Karena sudah disediakan laboratorium komputer yang lengkap dengan fasilitasnya. Selain itu, di Institut Pesantren KH.Abdul Chalim juga terdapat 1 ruang laboratorium komputer dengan 25 unit komputer.

2) Perancangan (Design)

Dilakukan dengan pembuatan alur pembelajaran, penyusunan isi media, penyusunan petunjuk praktikum, pembuatan desain tampilan media Pembuatan alur pembelajaran

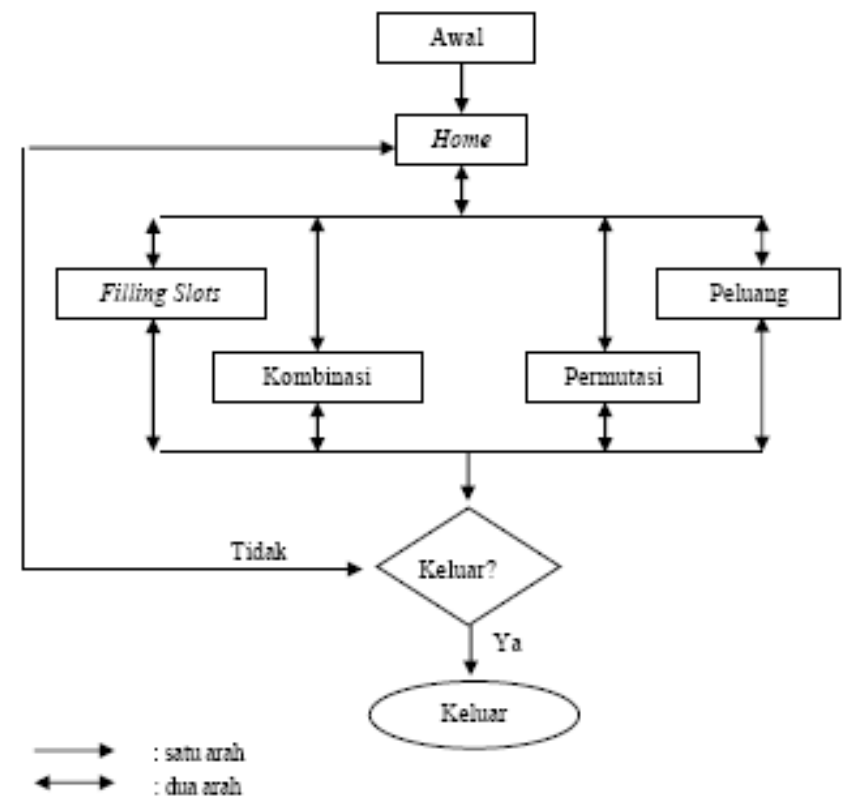

Gambar 1.Diagram Alir (Flow Chart) Media

b) Penyusunan isi media 
Media yang akan di buat ini terdiri dari tiga bagian, yaitu bagian awal/pembukaan, bagian inti media, dan bagian penutup.

c) Penyusunan Petunjuk Praktikum

Untuk mempermudah pemakaian media oleh mahasiswa, peneliti berusaha menyusunkan sebuah petunjuk praktikum yang kami kemas dengan nama "lembar kerja mahasiswa"

d) Pembuatan Desain Tampilan Media

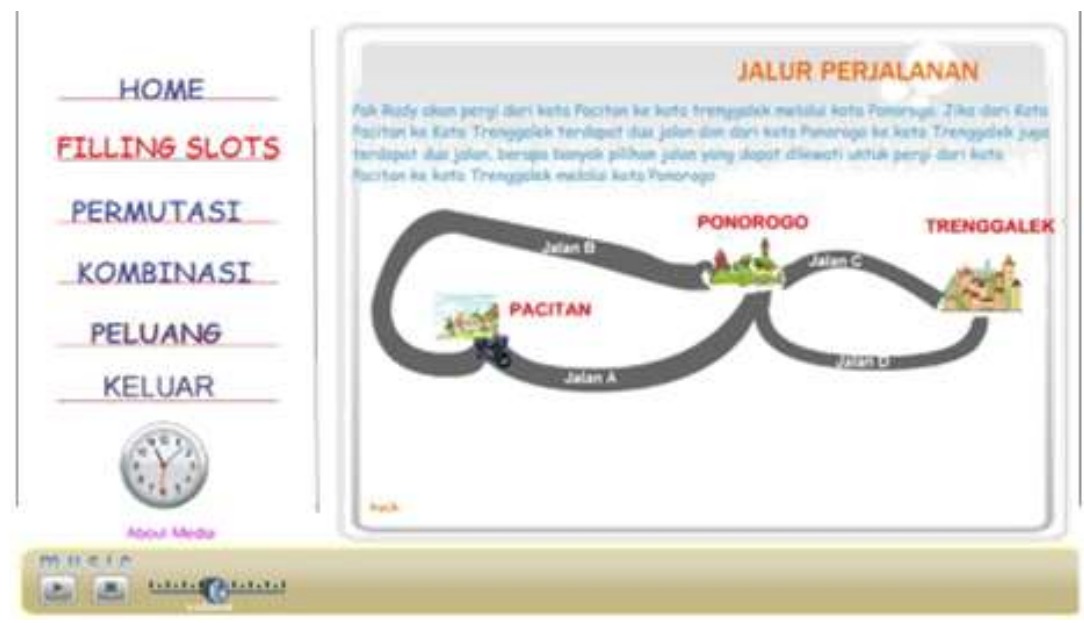

Gambar 2. Tampilan Media (FILLING SLOTS)

\section{3) Produksi (Development)}

Pembuatan media dilakukan secara bertahap yang dimulai dari pembuatan awal/pembukaan kemudian dilanjutkan bagian inti, dan terakhir pembuatan penutup. Program yang digunakan adalah Macromedia Flash 8. 
4) Implementasi (Implementation)

Penelitian ini bertujuan untuk mengembangkan media pembelajaran matematika berbasis multimedia interaktif dan melihat bagaimana tanggapan mahasiswa terhadap media tersebut.Data diperoleh dari angket evaluasi media dan ditambah dengan pengamatan dari para peneliti selama kegiatan berlangsung. Data yang diperoleh dari angket evaluasi media akan dianalisis kemudian akan digunakan untuk mengevaluasi media interaktif. Media akan direvisi apabila skor masing-masing item dari $75 \%$ skor maksimal, apabila skor lebih dari samadengan $75 \%$ maka media tidak akan direvisi. Karena kriteria itu menunjukkan bahwa media itu bagus dan layak digunakan. Sedangkan pengamatan digunakan untuk melihat tanggapan siswa dan sikap siswa terhadap media yang baru dikembangkan ini.

5) Evaluasi (Evaluation)

Evaluasi media didasarkan pada hasil angket evaluasi media. Dari hasil angket evaluasi media, media tidak perlu direvisi skor yang diperoleh masing-masing butir $\geq 75 \%$ dari skor maksimal atau lebih dari $228(75 \%$ $\square 304=228$ ).

\section{b. Evaluasi Hasil Media}

\section{Tabel 1}

Rekapitutasi Hasil Angket Evaluasi Media 


\section{Pernyataan CD pembelajaran}

No ini

Skor Persentase Revisi/

total

tidak

\begin{tabular}{llccc}
\hline 1 & Mudah digunakan & 261 & 85,86 & Tidak \\
\hline 2 & Media tersusun sistematis & 254 & 83,55 & Tidak \\
\hline 3 & LKS mudah dipahami & 229 & 75,33 & Tidak \\
\hline
\end{tabular}

LKS membantu penggunaan media

$\begin{array}{lllll}4 & \text { ini } & 253 & 83,22 & \text { Tidak }\end{array}$

\begin{tabular}{lllll}
\hline 5 & Urutan LKS sesuai & 258 & 84,87 & Tidak
\end{tabular}

\begin{tabular}{llll}
\hline 6 & Komposisi warna sesuai dan menarik 248 & 81,58 & Tidak
\end{tabular}

\begin{tabular}{llll}
\hline 7 & Pemilihan gambar sesuai dan menarik 253 & 83,22 & Tidak
\end{tabular}

\begin{tabular}{lllll}
\hline 8 & Animasi menarik & 250 & 82,24 & Tidak
\end{tabular}

Penggunaan tombol navigasi mudah

9

dipahami

$257 \quad 84,54$

Tidak

Warna, ukuran, letak tombol sesuai

dan

10

menarik

$243 \quad 79,93$

Tidak

Huruf, teks, dan kalimat mudah

\begin{tabular}{lllll}
11 & dibaca & 262 & 86,18 & Tidak \\
\hline 12 & Bahasa mudah dipahami & 246 & 80,92 & Tidak
\end{tabular}

13 Musik latar tidak mengganggu 
konsentrasi belajar

$246 \quad 80,92$

Tidak

Materi cocok untuk pembelajaran

14

\begin{tabular}{llccc} 
& Peluang & 254 & 83,55 & Tidak \\
\hline 15 & Materi lebih mudah dipahami & 248 & 81,58 & Tidak \\
\hline 16 & Memuat cukup luas cakupan materi & 236 & 77,63 & Tidak \\
\hline 17 & Membantu belajar mandiri & 254 & 83,55 & Tidak \\
\cline { 2 - 4 }
\end{tabular}

Media menumbuhkan cara berfikir

18

\begin{tabular}{llllll} 
kreatif & & & 254 & 83,55 & Tidak \\
\hline Media & membantu & belajar & Materi & &
\end{tabular}

19 Peluang $264 \quad 86,84 \quad$ Tidak

Media membantu dalam memahami

20 aplikasinya dalam kehidupan sehari-

hari

$256 \quad 84,21$

Tidak

Evaluasi media didasarkan pada hasil angket evaluasi media. Dari hasil angket evaluasi media, media tidak perlu direvisi skor yang diperoleh masing-masing butir $\geq 75 \%$ dari skor maksimal atau lebih dari $228(75 \% 304=228)$.

Berdasarkan kriteria skor dari suatu intrumen yang diungkapkan Suharsimi Arikunto (1998: 246), maka diputuskan bahwa media tidak ada yang direvisi. Karena ke 20 item angket tersebut memiliki prosentase di atas $75 \%$. 
Secara umum Multimedia Interaktif Peluang yang dikembangkan ini lebih menitikberatkan pada interaktivitas mahasiswa dalam menggunakan media ini, oleh karena itu media berisi permasalahan-permasalahan yang berkaitan dengan materi kombinatorika dan materi peluang pada mata kuliah teori peluang.

Dalam pelaksanaan implementasi terdapat beberapa kendala. Kendala yang dihadapi antara lain mahasiswa yang terbiasa dengan pembelajaran secara abstrak, sehingga peneliti terkadang kesulitan merubah mindset mahasiswa yang sudah terlanjur abstrak dan mahasiswa juga masih belum terbiasa dengan pembelajaran dengan menggunakan media interaktif sehingga waktu pertama kali menggunakan media mahasiswa kesulitan.Walupun demikian sebagai peneliti berusaha mendampingi dan mengarahkan dengan sebaik mungkin bagaimana menggunakan media tersebut sebagaimana mestinya. Memberikan panduan dan penjelasan jika ada yang merasa kesulitan dalam menangkap isi media. Sehingga pembelajaran dapat berjalan sesuai dengan yang diharapkan.Terbatasnya waktu pembelajaran yang disebabkan oleh waktu penggunaan laboratorium komputer yang terbatas karena berbenturan dengan jadwal dengan mata kuliah lain bahkan jurusan lain dalam menggunakan laboratorium. Dan ternyata kendala-kendala tersebut juga mempengaruhi proses pembelajaran. 


\section{E. KESIMPULAN DAN SARAN}

\section{Kesimpulan}

Berdasarkan hasil penelitian yang diperoleh, meskipun pada awalnya merasa kesulitan dengan metode pembelajaran, tetapi seiring dengan penyesuaian dari mahasiswa semuanya dapat diterima oleh mahasiswa dan tidak ada revisi.

\section{Saran}

a. Para mahasiswa diharapkan dapat melatih dirinya dalam menggunakan media pembelajaran yang berbasis multimedia interaktif agar lebih terbiasa

b. Dosen diharapkan lebih kreatif dalam menggunakan program matematika secara umum untuk meningkatkan pemahaman konsep pada mata kuliah tertentu

c. Dosen diharapkan lebih banyak menggunakan media interaktif dalam melaksanakan perkuliahan terutama pada mata kuliah yang cocok menggunakan media tersebut. 


\section{DAFTAR PUSTAKA}

Arsyad, A. (2002). Media Pembelajaran. Jakarta: PT RajaGrafindo Persada. Brynes, J.P. (2008). Cognitive development and dearning in instructional contexts. ( $3^{\text {rd }}$ ed.). Boston: Pearson Education.

Purwanto, N. (2000). Psikologi Pendidikan. Bandung: PT Remaja Rosdakarya. Ena, O.T. (2005). Membuat Media Pembelajaran Interaktif dengan Piranti

\section{Lunak Presentasi.}

(www.ialf.edu/kipbipa/papers/OudaTedaEna.doc).

Diakses tanggal 14 Maret 2014.

Priliyanti. (2012). Pengembangan Media Pembelajaran Matematika Berbasis Multimedia Interaktif pada Materi Turunan fungsi. AdmathEdu. Vol.2 No.2. Diakses tanggal 12 April 2014 dari http://admathedu.uad.ac.id/wp/

Purwanto. (2004). Pengembangan Multimedia Pembelajaran. Makalah disampaikan pada Lokakarya Pengembangan Media yang diselenggarakan oleh Jurusan Pendidikan Matematika FMIPA UNY pada 15 Mei 2004. 